\title{
Histological evaluation of swim bladder non- inflation in striped bass larvae Morone saxatilis
}

\author{
R. O. Bennett ${ }^{1}$, J. N. Kraeuter ${ }^{2}$, L. C. Woods III ${ }^{3}$, M. M. Lipsky ${ }^{1}$, E. B. May ${ }^{1}$ \\ ${ }^{1}$ Department of Pathology, University of Maryland, School of Medicine, Baltimore, Maryland 21201, USA \\ ${ }^{2}$ Crane Aquaculture Facility, Baltimore Gas \& Electric, Baltimore, Maryland 21202 , USA
}

\begin{abstract}
Non-inflation of the swim bladder is a common anomaly associated with cultured larval striped bass Morone saxatilis. Histological examination of tank-cultured larvae revealed $30 \%$ had noninflated swim bladders. Two distinct morphological types of abnormal swim bladders were observed glandular with marked fibrosis, and degenerative with severe fibrosis. Histological observations suggest that non-inflation of the swim bladder is irreversible.
\end{abstract}

\section{INTRODUCTION}

A common lesion found in cultured striped bass larvae Morone saxatilis is non-inflation of the swim bladder. The significance of this anomaly to the long-term survival of striped bass is unresolved. Reports of this condition have been made on hatchery-reared sea bream Sparus aurata, red sea bream Pagrus major, and sea bass Dicentrarchus labrax (Paperna 1978, Kitajima et al. 1981, Weppe \& Bonami 1981). Failure of striped bass larvae to inflate their swim bladder has been described (Doroshev \& Cornacchia 1979, Bulak \& Heidinger 1980); however clear morphological and pathological descriptions have not been reported. Doroshev (1970) stated that the incidence of anomalous swim bladders in striped bass normally ranges from 20 to $70 \%$ but can be as high as $90 \%$. According to field and hatchery personnel, the condition can be a significant problem.

Presently it is not known whether the swim bladder lesions are reversible, or represent an end stage. This study was conducted to determine if the anomalous swim bladders exhibit characteristics suggesting that, under appropriate culture conditions, normal form and function of the swim bladders could be restored.

\section{MATERIALS AND METHODS}

During April and May 1985, 24 h old striped bass larvae were transported from the Del Marva Ecological Laboratories to the Baltimore Gas \& Electric Com- pany's Crane Aquaculture Facility (Baltimore, Maryland, USA). These larvae were part of a study to evaluate normal histological development of striped bass larvae. Parental stocks were derived from the Nanticoke River, a tributary of Chesapeake Bay. At the hatchery, eggs and milt were manually stripped from broodfish and eggs were fertilized using the dry method (Piper et al. 1982). A sampling protocol was designed to determine salient developmental features and to detect diseases as they appeared under culture conditions. Sibling larvae were maintained in a flowthrough $1.8 \mathrm{~m}$ diameter circular tank with the flow adjusted to $7.51 \mathrm{~min}^{-1}$. Five larvae were removed twice daily, at 0800 and $1700 \mathrm{~h}$, from each of 2 tanks for a total of $22 \mathrm{~d}$. Larvae were placed into a $4 \%$ formaldehyde and $1 \%$ glutaraldehyde $(4 \mathrm{~F}-1 \mathrm{G})$ fixative (McDowell \& Trump 1976) and processed for light and electron microscopy. Samples were post-fixed in osmium tetroxide and uranyl acetate, dehydrated in ethanol and embedded in Epon. Semi-thin sections (0.5 to $1.0 \mu \mathrm{m}$ thick) were stained with toluidine blue for examination under a light microscope.

\section{RESULTS}

Following routine evaluations it was determined that $30 \%$ of the striped bass larvae examined exhibited uninflated swim bladders. In many cases the anomalous swim bladders were markedly fibrotic and exhibited cellular degeneration and necrosis making identification difficult. Two morphological types of anomal- 


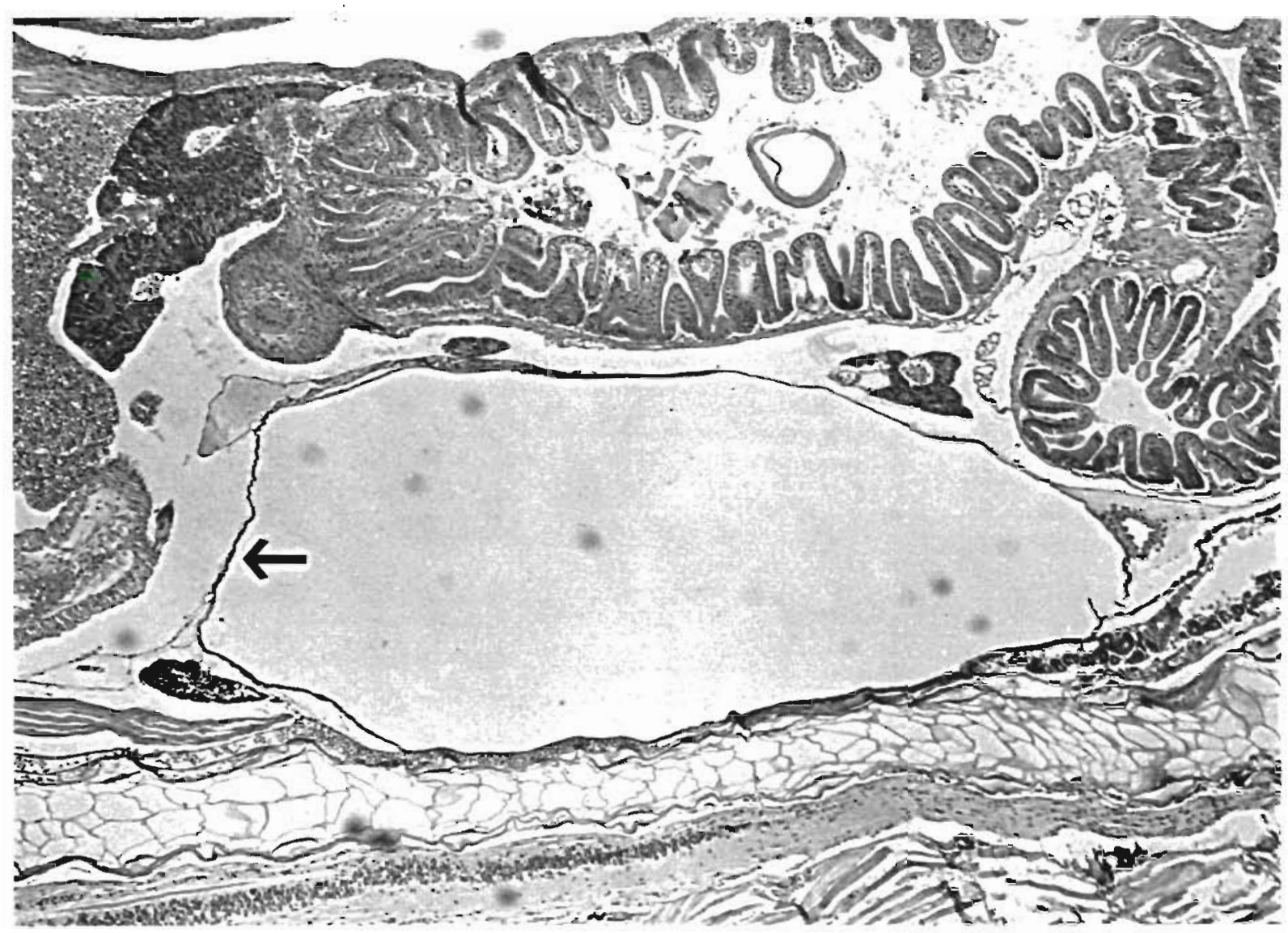

Fig. 1. Morone saxatilis. Normal swim bladder (arrow) in an $18 \mathrm{~d}$ old larval striped bass $(\times 100)$

ous swim bladders were observed and are described below. A normal swim bladder is presented for comparative purposes (Fig. 1).

\section{Type 1. Glandular swim bladder with marked fibrosis}

A single mass of cells on sagittal section (Fig. 2 A) or 2 distinct masses on cross section (Fig. 2 B) were observed. The dorsal mass appeared larger and was separated from the ventral mass by fibrosis. Both masses consisted of polygonal gland-like cells. Cells of the dorsal mass were pleomorphic and demonstrated a wide range of cytoplasmic staining intensities. The nuclei appeared normal and only a minimal amount of necrosis was observed. A heavy fibrotic sheath, variable in thickness, surrounded the dorsal mass. Melanosomes were commonly observed within the dorsal aspects of the fibrotic sheath. The smaller ventral mass consisted of uniform cells containing densestaining cytoplasm and normal-appearing nuclei. A well-formed pneumatic duct was not observed in any of the cases examined.
Type 2. Degenerative swim bladder with severe fibrosis

The difference between this glandular mass and that previously described was the degree of cellular degeneration. Degeneration was severe with the glandular mass exhibiting karyorrhexis and karyolysis. In severe cases the glandular mass was replaced by fibroblasts (Fig. 3).

Striped bass larvae examined ranged in age from 2 to $22 \mathrm{~d}$ post-hatch. Swim bladders were first observed in 2 d post-hatch larvae. Non-inflation of the swim bladder was first observed in $4 \mathrm{~d}$ post-hatch larvae. At this time, the anomalous swim bladder observed was Type 1 , glandular with marked fibrosis. The second type of uniflated swim bladder (Type 2), glandular with severe fibrosis, was first seen in larvae at $7 \mathrm{~d}$ post-hatch. Type 1 and 2 swim bladders were observed in larvae at 21 and $22 \mathrm{~d}$ post-hatch, respectively. Of the anomalous swim bladders observed $71 \%$ were of Type 1 and $29 \%$ were of Type 2. 


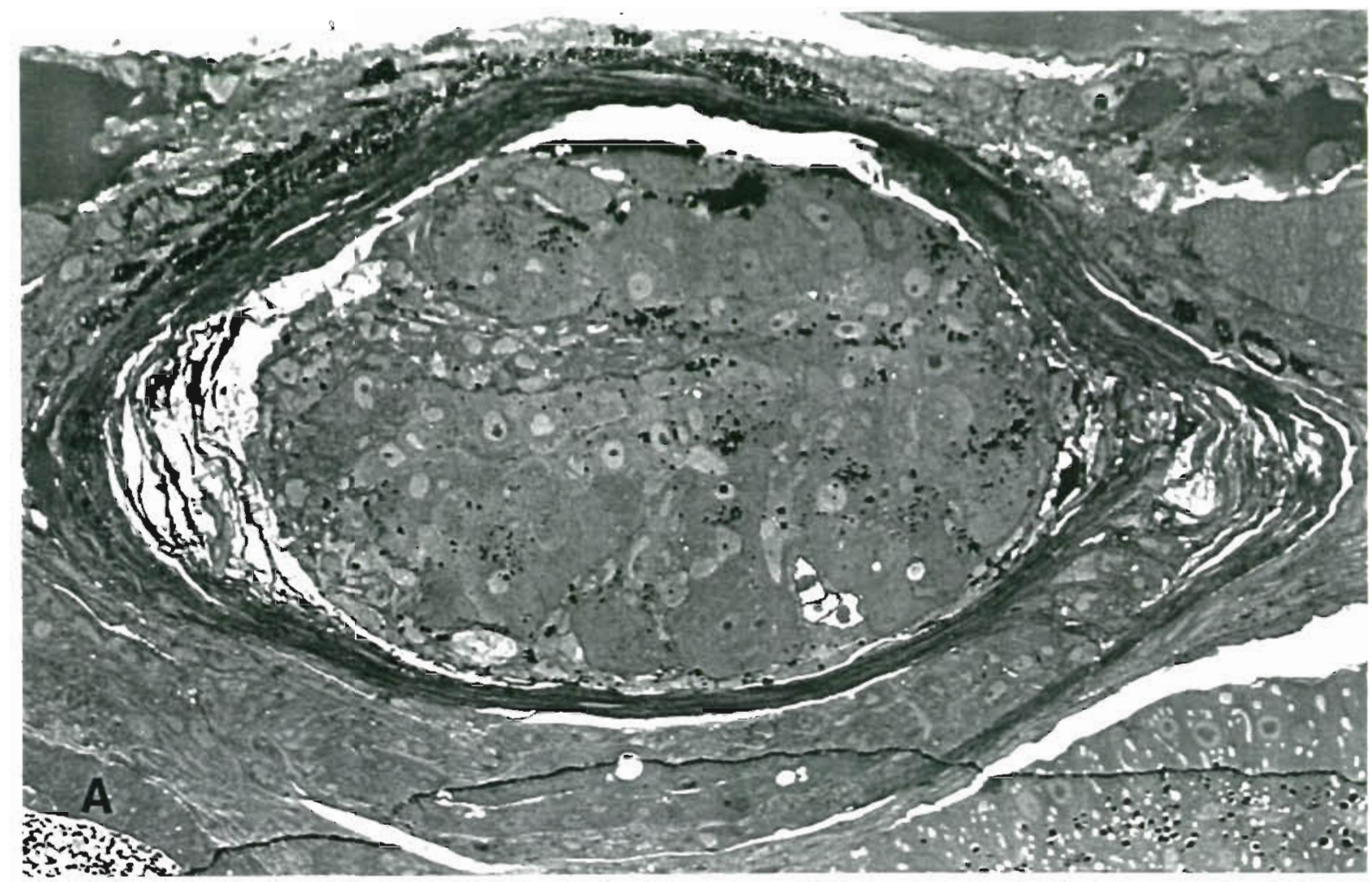

Fig. 2. Morone saxatilis. Glandular swim bladder with marked fibrosis. A single mass of cells can be observed on sagittal section (A) or as 2 distinct masses on cross section (B). On cross section, the dorsal mass (large arrow) appears to be the larger of the two and is separated from the smaller ventral mass (small arrow) by fibrosis. This lesion was observed in an $11 \mathrm{~d}$ old larva (x 100)

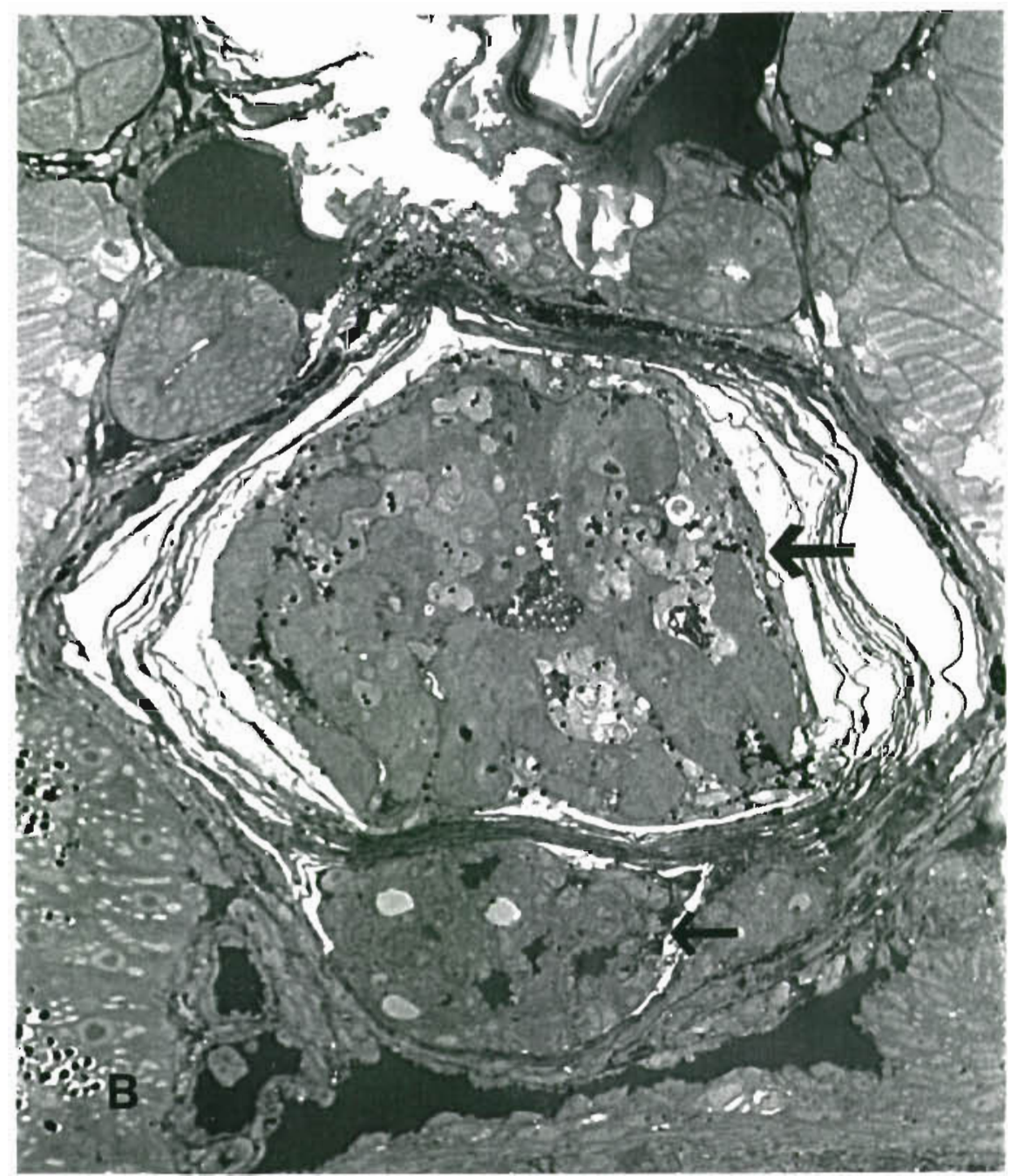




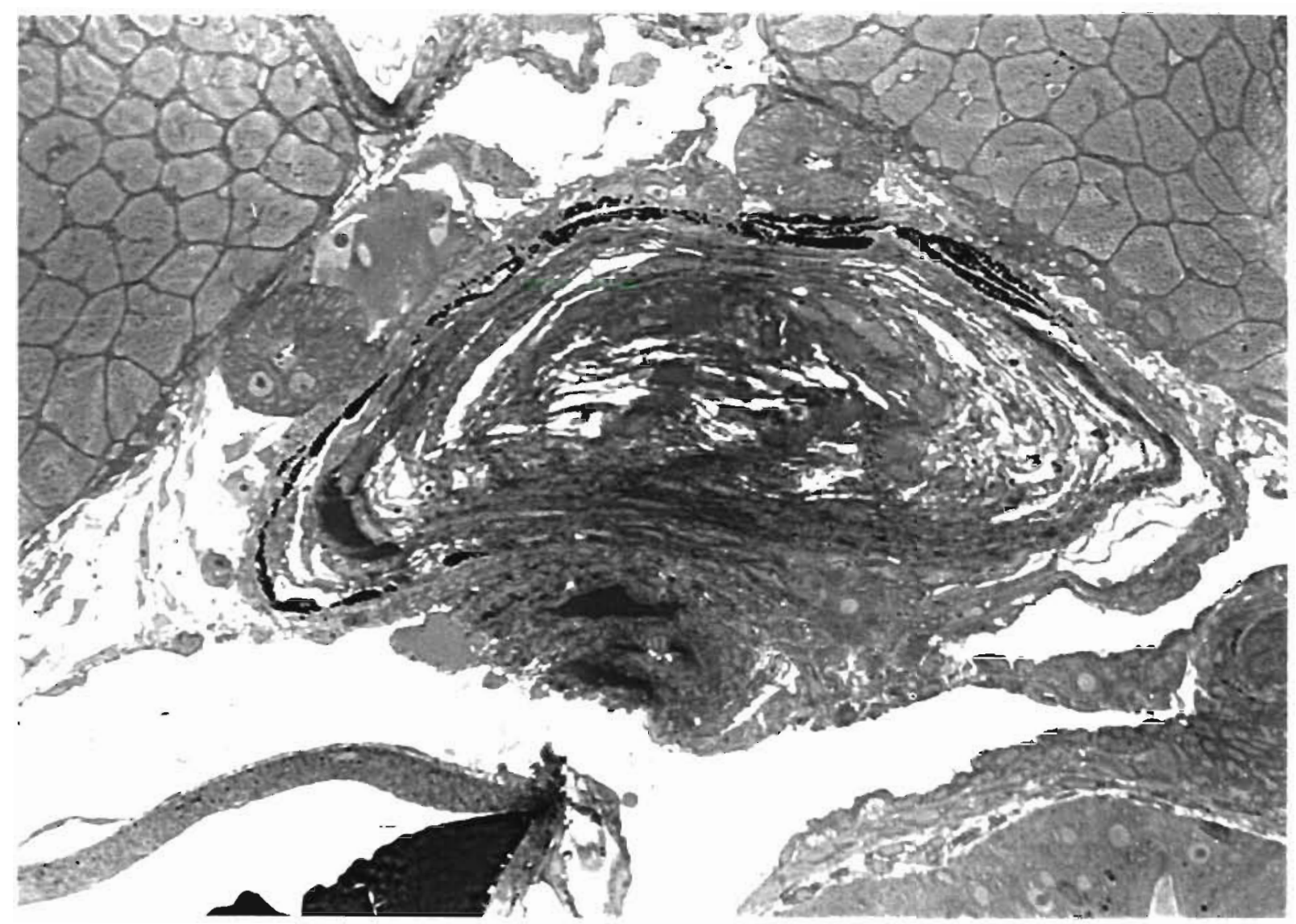

Fig. 3. Morone saxatilis. Degenerative swim bladder with severe fibrosis. Severe degenerative changes are associated with this swim bladder lesion. Cells making up the mass were either necrotic or were replaced by fibrotic tissue. This lesion was observed in a $9 \mathrm{~d}$ old larva $(\times 100)$

\section{DISCUSSION}

The etiological agents or conditions responsible for non-inflation of the swim bladder are presently unknown. Factors that have been implicated include failure of pneumatic duct formation, lack of dissolved oxygen (Doroshev \& Cornacchia 1979), failure of gas secretion (Doroshev et al. 1981) or genetic factors associated with skeletal deformities (Paperna 1978). Lordosis is commonly encountered in specimens with uniflated swim bladders. Kitajima et al. (1981) demonstrated that gulping of air at the water surface is essential for initial swim bladder inflation in red sea bream Pagrus major. None of the larvae in their study had inflated swim bladders after $7 \mathrm{~d}$ when they were prevented from gulping air. In addition, Kitajima et al. (1981) observed that $90 \%$ of the fish developed lordotic deformities by $40 \mathrm{~d}$ post-hatching. They suggested that the skeletal deformities were the result of noninflation of the swim bladder.

Observations on the swimming behavior of striped bass larvae has suggested that the lack of a functional swim bladder results in additional expenditure of energy. The increased energy demand results in exhaustion, and larvae settle to the bottom of the culture tanks. Increased mortality may result, although large numbers (5809 ind) of striped bass fingerlings without inflated swim bladders have reached lengths of $15 \mathrm{~cm}$ at the Baltimore Gas \& Electric Company's Crane Aquaculture Facility. All of these fish exhibit spinal deformities and swim in a characteristic 'head up' posture. Larger fish have not been observed with this condition, since fish with uninflated swim bladders are removed from the hatchery during routine grading practices.

Histological observations of striped bass larvae in our study are consistent with those of Doroshev \& Cornacchia (1979) and Doroshev et al. (1981) for tilapia Tilapia mossambica and striped bass, respectively. Due to the severity of the lesions it is evident that the first development of non-inflation of the swim bladder occurs prior to 4 d post-hatch. Approximately $15 \%$ of cases with Type 1 swim bladders appeared to be progressing towards a 
Type 2 swim bladder. Further studies are in progress to confirm this observation. Observations presented in this report suggest that the anomalies are irreversible. Fibrosis may or may not be the final outcome; however, the prevalence of fibrosis is high (29\%) suggesting that this may be an end stage for such anomalies.

\section{LITERATURE CITED}

Bulak, J. S., Heidinger, R. C. (1980). Developmental anatomy and inflation of the gas bladder in striped bass, Morone saxatilis. Fish. Bull. U. S. 77: 1000-1003

Doroshev, S. I. (1970). Biological features of the eggs, larvae and young of the striped bass [Roccus saxatilis (Walbaum)] in connection with the problem of its acclimatization in the USSR. J. Ichthyol. 10: 235-248

Doroshev, S. I., Cornacchia, J. W. (1979). Initial swim bladder inflation in the larvae of Tilapia mossambica (Peters) and Morone saxatilis (Walbaum). Aquaculture 16: 57-66
Doroshev, S. I., Cornacchia, J. W., Hogan, K. (1981). Initial swim bladder inflation in the larvae of physoclistous fishes and its importance for larval culture. Rapp. P.-v. Réun. Cons. int. Explor. Mer 178: 495-500

Kitajima, C., Tsukashima, Y., Fujita, S., Watanabe, T., Yone, Y. (1981). Relationship between uninflated swim bladders and lordotic deformity in hatchery-reared red sea bream Pagrus major. Bull. Jap. Soc. scient. Fish. 47: 1289-1294

McDowell, E. M., Trump, B. F. (1976). Histologic fixatives suitable for diagnostic light and electron microscopy. Arch. Pathol. Lab. Med. 100: 405-414

Paperna, I. (1978). Swimbladder and skeletal deformations in hatchery bred Sparus aurata. J. Fish Biol. 12: 109-114

Piper, R. G., McElwain, I. B., Orme, L. E., McCraren, J. P., Fowler, L. G., Leonard, J. R. (1982). Fish Hatchery Management. U. S. Department of the Interior, Fish and Wildlife Service, Washington, D. C.

Weppe, M., Bonami, J. R. (1981). Non-inflation of the swimbladder in hatchery-reared sea bass and sea bream: a significant problem in marine aquaculture. Bull. Eur. Ass. Fish Pathol. 3: 59-60

Responsible Subject Editor: Professor O. Kinne; accepted for printing on August 27, 1987 